University of Nebraska - Lincoln

DigitalCommons@University of Nebraska - Lincoln

\title{
Mouse $\times$ pig chimeric antibodies expressed in baculovirus retain the same properties of their parent antibodies
}

Ana M. Jar

University of Nebraska - Lincoln

Fernando A. Osorio

University of Nebraska - Lincoln, fosorio1@unl.edu

Osvaldo J. López

University of Nebraska - Lincoln, osvaldo.lopez@wright.edu

Follow this and additional works at: https://digitalcommons.unl.edu/vetscipapers

Part of the Veterinary Medicine Commons

Jar, Ana M.; Osorio, Fernando A.; and López, Osvaldo J., "Mouse × pig chimeric antibodies expressed in baculovirus retain the same properties of their parent antibodies" (2009). Papers in Veterinary and Biomedical Science. 116.

https://digitalcommons.unl.edu/vetscipapers/116

This Article is brought to you for free and open access by the Veterinary and Biomedical Sciences, Department of at DigitalCommons@University of Nebraska - Lincoln. It has been accepted for inclusion in Papers in Veterinary and Biomedical Science by an authorized administrator of DigitalCommons@University of Nebraska - Lincoln. 
Published in Biotechnology Progress 25:2 (2009), pp. 516-523; doi: 10.1002/btpr.113 Copyright @ 2009 American Institute of

Chemical Engineers (AIChE); published by John Wiley Inc. Used by permission. http://www.interscience.wiley.com

Funding for the research reported in this article was provided by Sygen International, National Research Initiative of the USDA Cooperative State Research, Education and Extension Service-Grant Number: 2004-35605-14197, and the PRRS Coordinated Agricultural Project.

\title{
Mouse $\times$ pig chimeric antibodies expressed in baculovirus retain the same properties of their parent antibodies
}

\author{
Ana M. Jar, ${ }^{a}$ Fernando A. Osorio, a and Osvaldo J. López ${ }^{\mathrm{b}}$ \\ a Department of Veterinary and Biomedical Sciences, University of Nebraska-Lincoln, Lincoln, NE 68583 \\ ${ }^{\mathrm{b}}$ Department of Veterinary and Biomedical Sciences, University of Nebraska-Lincoln, NE 68583, \\ and Wolf Biotech, Marquette, MI 49855 \\ Corresponding author - Osvaldo J. López, 140E White Hall, Boonshoft School of Medicine, \\ Wright State University, Dayton, OH 45435; email osvaldo.lopez@wright.edu \\ Current address for A. M. Jar - School of Veterinary Sciences, Universidad de Buenos Aires, Buenos Aires, Argentina
}

\begin{abstract}
The development of hybridoma and recombinant DNA technologies has made it possible to use antibodies against cancer, autoimmune disorders, and infectious diseases in humans. These advances in therapy, as well as immunoprophylaxis, could also make it possible to use these technologies in agricultural species of economic importance such as pigs. Porcine reproductive and respiratory syndrome virus (PRRSV) is an arterivirus causing very important economic losses to the industry. Passive transfer of antibodies obtained by biotechnology could be used in the future to complement or replace vaccination against this and other pig pathogens. To this end, we constructed and studied the properties of chimeric mouse $\times$ pig anti-PRRSV antibodies. We cloned the constant regions of gamma-1 and gamma-2 heavy chains and the lambda light chain of pig antibodies in frame with the variable regions of heavy and light chains of mouse monoclonal antibody ISU25C1, which has neutralizing activity against PRRSV. The coding regions for chimeric IgG1 and IgG2 were expressed in a baculovirus expression system. Both chimeric antibodies recognized PRRSV in ELISA as well as in a Western-blot format and, more importantly, were able to neutralize PRRSV in the same fashion as the parent mouse monoclonal antibody ISU25C1. In addition, we show that both pig IgG1 and IgG2 antibodies could bind complement component C1q, with IgG2 being more efficient than IgG1 in binding C1q. Expressing chimeric pig antibodies with protective capabilities offers a new alternative strategy for infectious disease control in domestic pigs.
\end{abstract}

Keywords: pig chimeric antibodies, PRRSV, baculovirus

\section{Introduction}

The production of antibodies using recombinant DNA technologies for therapy and prophylaxis in humans has blossomed in the last decade, opening the door to its use in the control of infectious diseases in animals. With such goal in mind, it becomes important to test the feasibility of this technology in the production of recombinant antibodies from animals of economic importance.

Porcine reproductive and respiratory syndrome (PRRS) is the most important infectious disease in swine, producing losses higher than 600 million dollars per year to the industry. ${ }^{1}$ Porcine reproductive and respiratory syndrome virus (PRRSV) is the etiological agent of PRRS. Currently, attenuated vaccines are in use to attempt protecting against PRRSV infection. Such protection is more successful in case of infection with PRRSV strains homologous to the vaccine strain, but not as efficient in the case of heterologous strains. Therefore, the high heterogeneity of PRRSV field isolates makes it difficult to control this virus with the current vaccines. ${ }^{2,3}$ In fact, protective vaccines or immunization regimes inducing the appearance of PRRSV-neutralizing antibodies against the homologous strain are associated with protection. ${ }^{4,5}$ The role of neutralizing antibodies in protection of pregnant sows from abortion ${ }^{6}$ and piglets from viremia, viral spread, and shedding ${ }^{7}$ by passive transfer of immunoglobulins enriched in neutralizing antibody activity has been shown previously by us. These results suggest that neutralizing antibodies could be used as immunoprophylactic pharmaceuticals against PRRS virus infection.

The use of monoclonal antibodies against infectious diseases has been envisioned since the development of this technology. ${ }^{8,9}$ However, it took almost 20 years until a commercial product of this sort was available to intervene in human 
infections..$^{10}$ One of the main problems of this approach has been the immune response of the nonmurine host against mouse monoclonal antibodies. This problem was first overcome by using mouse $\times$ human chimeric antibodies and later by "humanizing" mouse monoclonal antibodies (reviewed in Reference 11). For example, humanized monoclonal neutralizing antibody Palivizumab (Synagis ${ }^{\circledR}$ ) directed against the F protein of respiratory syncitial virus (RSV) was the first antibody used against infectious diseases, which has proven successful in preventing infection of infants at risk. ${ }^{12}$ Currently, many antibodies obtained by recombinant DNA technology are available in human medicine against cancer, autoimmune, and infectious diseases. The knowledge accumulated about mouse and human antibodies' sequence, structure, and function of the different domains of the molecule has been important in the design and development of this new kind of prophylactic and therapeutic biologics.

Herein we show that it is feasible to produce mouse $x$ pig chimeric antibodies in a baculovirus expression system that maintains the same properties of the Fv from mouse antibodies. We also show the ability of the Fcs of pig IgGs to bind C1q of complement. Such preservation of the properties of the mouse $\times$ pig chimeric antibodies allow for a new possible strategy against PRRSV in pigs to provide immediate prevention of infection.

\section{Materials and Methods}

Cloning of constant regions of porcine lambda, gamma-1 and gamma-2 chains

Sequences encoding porcine heavy and light chain constant regions were amplified from RNA, using primers based on the published sequences for gamma and lambda chains. ${ }^{13,14}$ Standard cloning procedures were carried out. ${ }^{15}$ Briefly, total RNA was isolated with TRIZOL ${ }^{\mathrm{TM}}$ (Gibco-Invitrogen, CA, USA) from spleen obtained by necropsy of a healthy, 4-month-old large-white pig. Reverse transcription reactions were performed using SuperScript ${ }^{\mathrm{TM}}$ (Invitrogen, CA, USA) for $50 \mathrm{~min}$ at $42^{\circ} \mathrm{C}$ and primers for porcine gamma-1 and gamma-2 (5'-TATGTACACAGCGCTGGGGC$\left.3^{\prime}\right)$ and for porcine lambda chain (Oligo-dT). PCR were performed using Pfu DNA Polymerase (Stratagene, CA, USA) in the manufacturer's buffer using forward 1-19 Nhe I (5'-GCTAGCGCCCCCAAGACGGCCCCAT-3') and reverse 977-999 Kpn I (5'-GGTACCGCAGCGGGTGGCTCATTTACCCT-3') primers for porcine gamma-1, forward 1-19 Kpn I (5'-GCTAGCGCCCCCAAGACGGCCCCAT-3') and reverse 969-

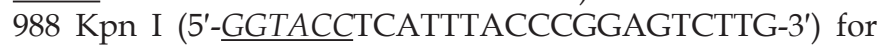
porcine gamma-2, and forward 19-42 Hpa I (5'-ACT GTTAACCTCTTCCCGCCCTCC-3') and reverse 301-318 Bgl II (5'-AGATCTCTAGGCGCACTCGGAGGG-3') for lambda constant chains. Recognition sites for the restriction endonucleases are shown in italic font. The three DNA fragments were cloned in pGEM®-T Easy Vector (Promega, WI, USA).

\section{Cloning of variable regions of murine lambda and gamma-1 chains}

Heavy and light chain variable regions were amplified from hybridoma ISU25C1. ${ }^{16}$ ISU25C1 monoclonal antibodies use gamma- 1 and lambda chains and recognize an epitope located at the ectodomain of glycoprotein GP5 from PRRSV strain KY35 (NVLS 46907). Mouse heavy chain vari- able region was amplified by RACE-PCR (5' RACE System for Rapid Amplification of cDNA Ends, Version 2.0; Invitrogen) from total RNA. cDNA was synthesized using a primer annealing between nucleotides 82 and 99 of the mouse antibody gamma-1 chain (5'-GAAATAGCCCTTGACCAG-3'). PCR amplification of dC-tailed cDNA was performed using Abridged Anchor Primer (provided by the kit) and a reverse primer annealing between nucleotides 40 and 62 (5'-GAGTTAGTTTGGGCAGCAGATCC-3'). Whole mouse lambda chain was amplified by RT-PCR. cDNA was synthesized using oligo-dT, and PCR was performed with a forward primer 1-18 (5'-ATGGCCTGGAYTTCACTT-3') designed based on the sequences for leader peptides of mouse lambda- 1 and lambda-2 variable regions ${ }^{17,18}$ and reverse primers for mouse lambda-1 687-705 (5'-CTAGGAACAGTCAGCACG-3') and mouse lambda 2 685-705 (5'-TTAGAGACATTCTGCAGGAGA-3'), based on the published antibody lambda constant regions. ${ }^{19}$ The amplified DNA fragment was cloned in pGEM-T Easy Vector (Promega Corp.).

\section{Construction of recombinant baculoviruses for the production of chimeric IgG1 and IgG2}

The assembly of variable and constant heavy and light chains as fusion proteins is described in the "Results" section. The DNA sequence coding for complete chimeric light chain was released from pGEM-T Easy vector (Promega) and cloned at the Bgl II site in baculovirus transfer vector pAcUW51 (Pharmingen, CA, USA) to obtain vector pAcISU25-PIG $\lambda$. DNA sequence for complete chimeric heavy chains (gamma-1 and gamma-2) were then released from TA vector and cloned at the BamH I site in vector pAc-ISU25PIG $\lambda$, to obtain vectors pAc-ISU25-PIG $\lambda / \gamma 1$ and pAc-ISU25$\mathrm{PIG} \lambda / \gamma 2$, respectively, carrying the encoding sequences for chimeric [mouse $\times$ pig] IgG1 and IgG2 complete antibodies. The inserts were sequenced seven times and no unexpected mutations were introduced during the cloning procedure.

\section{Production and purification of chimeric IgG1 and IgG2}

Sf 9 cells were cotransfected with vectors pAc-ISU25$\mathrm{PIG} \lambda / \gamma 1$ or pAc-ISU25-PIG $\lambda / \gamma 2$ and BaculoGold $®$ linearized baculovirus DNA (Pharmingen) by the calcium phosphate method, following the instructions of the manufacturer. Recombinant viruses produced by homologous recombination and carrying the sequences for chimeric IgG1 and IgG2 were obtained from supernatants 4 days post-transfection, plaque-purified, and amplified to produce a high titer viral stock. Intracellular expression of chimeric immunoglobulins in infected cells was assessed by immunofluorescence using a FITC-conjugated anti-pig IgG (H+L) (KPL, MD, USA). Sf 9 cultures at a density of $2 \times 10^{6}$ cells $/ \mathrm{mL}$ were infected with recombinant viruses at a multiplicity of infection (m.o.i.) of 5 and grown in serum-free medium (Sf-900 II SFM, Gibco-Invitrogen) at $26^{\circ} \mathrm{C}$ over a shaking platform. After 5 days of culture ( $50 \%$ of dead cells), cultures were harvested and clarified by centrifugation at $10,000 \mathrm{~g}$ for $5 \mathrm{~min}$. The virus and other large particles were pelleted by ultracentrifugation at $40,000 \mathrm{~g}$ for $30 \mathrm{~min}$. The supernatants were concentrated by ultrafiltration using 80-mL recipients (Centricon-80, Millipore Corp., MA). Samples were centrifuged at 3,000g for 2 $h$, resuspended in PBS, and centrifuged again to concentrate 100 times the antibodies in the supernatant. Alternatively, 
recombinant antibodies were applied to Protein A-Agarose packed in Econo-columns (Bio-Rad Laboratories, CA). Bound IgG was eluted with $0.1 \mathrm{M}$ glycine buffer $\mathrm{pH} 2.5$.

\section{Characterization of chimeric IgGs by SDS-PAGE and Western blot analysis}

Standard procedures were performed according to Harlow and Lane. ${ }^{20}$ Chimeric IgG1 and IgG2 affinity-purified by Protein-A columns and controls, $500 \mathrm{ng}$ of protein per lane, were analyzed under reducing conditions on $15 \%$ polyacrylamide gels stained with Coomassie Brilliant Blue R250 (Pierce, IL, USA). Porcine serum antibodies used as positive controls were purified by ammonium sulfate precipitation and affinity-purification through protein A-agarose columns. Supernatant from Sf9 cells infected with a recombinant baculovirus producing an unrelated protein (Xyl-E) was used as negative control. Western blots were performed using HRPconjugated antibodies and developed by chemiluminescence (Lumi-Glo®, KPL) on a classic autoradiography single-emulsion film (Midwest Scientific, MO, USA).

Chimeric antibodies chains were identified in Western blot analyses by an anti-porcine IgG (KPL) and commercial monoclonal antibodies identified as heavy-chain specific for porcine IgG1 (Cat. no. MCA635; clone $\mathrm{K} 1393 \mathrm{C} 8$ ) and porcine IgG2 (Cat. no. MCA636; clone K68 Ig2) and specific for porcine Lambda chain (Cat. no. MCA633; clone K139 3E1) from Serotec Ltd., Oxford, UK. The three monoclonal antibodies have an IgG1/kappa isotype; then, a rat anti-mouse kappa horseradish peroxidase (HRP)-conjugated antibody (Cat. no. MCA1291P, Serotec Ltd.) was used as secondary antibody. A Western blot using glycosilated and deglycosilated porcine total IgG was performed to assess whether different glycosilation pattern in insect cells could affect the recognition of monoclonal anti-porcine IgG1 or IgG2. Two polyclonal IgG samples, purified from serum pools, were treated with $N$ glycanase [Peptide- $N^{4}$-(acetyl- $\beta$-glucosaminyl)-asparagine amidase] (PROzyme, CA). Two micrograms of treated and untreated IgG were run on a $10 \%$ polyacrylamide gel, and its Western blot was performed as described earlier.

\section{Production of PRRS virus}

PRRSV strain KY35 (NVLS 46907) was used as antigen throughout this work. Virus was grown in MARC-145 cells infected at an m.o.i. of 0.1 when cultures reached a confluence of $90-95 \%$ and harvested when the cytopathic effect reached $80 \%$ ( $\sim 5$ days p.i.). PRRSV was used either as a clarified suspension (cell associated virus: CAV) or purified by ultracentrifugation on a $40 \%$ sucrose cushion. Peptide S4 (SHITSYPAYFWC), a mimotope corresponding to epitope B on glycoprotein GP5 from PRRSV strain KY35, was produced by chemical synthesis.

\section{PRRSV-ELISA}

The ability of chimeric IgG1 and IgG2 to recognize complete virus was assessed by ELISA analysis. Chimeric antibodies from ultrafiltered supernatants were used as primary antibodies, followed by a goat anti-porcine IgG, HRP conjugated (KPL Inc.). Monoclonal antibody ISU25C1 was used as positive control, followed by a HRP-conjugated goat antimouse IgG (KPL Inc.). Ultrafiltered supernatant from Xyl-E producing Sf9 cells was used as negative control.

Reactions were performed using standard procedures. ${ }^{20}$ ELISA plates (Immulon $2 \mathrm{HB}$; ThermoElectron Corp., MA, USA) were coated with $5 \mu \mathrm{g}$ of CAV-PRRSV or uninfected cells in sodium carbonate buffer, $\mathrm{pH}$ 9.6. Chimeric antibodies or control Xyl-E were detected with a HRP-conjugated antiporcine IgG $(\mathrm{H}+\mathrm{L})$ antibody (KPL Inc.), and monoclonal antibodies were detected with an HRP-conjugated anti-mouse $\operatorname{IgG}(\mathrm{H}+\mathrm{L})$ antibody (KPL Inc.), both at a dilution 1:1,000. Reactions were developed with ABTS (KPL Inc.), stopped with $1 \% \mathrm{SDS}$ and read at $410 \mathrm{~nm}$. The absorbance read for PRRSVinfected cells was compared with the absorbance read for MARC-145 non-infected cells. Values of optical densities (ODs) read at $410 \mathrm{~nm}$ are expressed as corrected OD, calculated as $1 / 2\left[\left(\mathrm{OD} M_{\mathrm{s}}-\mathrm{OD} M_{\mathrm{c}}\right)+\left(\mathrm{OD} m_{\mathrm{s}}-\mathrm{OD} m_{\mathrm{c}}\right)\right]$, where $M_{\mathrm{s}}$ and $m_{\mathrm{s}}$ are the maximum and minimum values for the samples while $M_{\mathrm{c}}$ and $m_{\mathrm{c}}$ are the maximum and minimum values for the controls, respectively.

\section{PRRSV-epitope B ELISA}

A peptide-ELISA was performed to determine the ability of mouse $\times$ pig chimeric antibodies to recognize peptide $\mathrm{S} 4$ (SHITSYPAYFWC), as described earlier. ${ }^{21}$ Reacti-Bind Maleimide-Activated Plates (Pierce Biotechnology, Rockford, IL) were coated during $6 \mathrm{~h}$ with $2.5 \mu \mathrm{g}$ of either peptide $\mathrm{S} 4$ or irrelevant peptide P7 (QRAYLELPPWPPC) in PBS at pH 6.8 . Both peptides carry a terminal cysteine that allows binding to activated plates through stable thio-ether bonds at neutral $\mathrm{pH}$. Free maleimide groups were blocked by 1-h incubation of $10 \mathrm{\mu g} / \mathrm{mL}$ cysteine- $\mathrm{HCl}$ in PBS at $\mathrm{pH}$ 6.8. After a second blocking step with $10 \%$ skim milk in PBS, ELISA was carried out following the ELISA protocol described earlier. Again, values of absorbance at $410 \mathrm{~nm}$ were expressed as corrected $\mathrm{OD}$ as described earlier.

\section{Western blot analysis}

Western blots were performed with CAV-PRRSV as well as sucrose-purified PRRSV. Chimeric antibodies were detected with an HRPO-conjugated anti-porcine IgG $(\mathrm{H}+\mathrm{L})$ antibody (KPL Inc.) while monoclonal antibody ISU25C1 was detected with an HRP-conjugated anti-mouse $\operatorname{IgG}(\mathrm{H}+\mathrm{L})$ antibody (KPL Inc), both at a dilution 1:1,000. Reactions were developed by chemiluminescence or through a precipitating substrate (TMB 1-component Membrane Peroxidase Substrate; KPL Inc.).

\section{Neutralization of PRRSV}

The efficiency of chimeric antibodies on PRRSV neutralization was evaluated through a fluorescent foci reduction assay measured $24 \mathrm{~h}$ p.i. A viral focus was defined as four or more infected cells identified by an immunofluorescence reaction in the cell cytoplasm. PRRSV was used at a concentration of 50-100 foci forming units (FFU) in a volume of 50 $\mu \mathrm{L}$. The percent of neutralization was obtained comparing the average foci number detected when ultrafiltered supernatants with chimeric IgG1 and IgG2 were added to PRRSV (sample), vs. the average foci number documented when only RPMI medium was added (control). Ultrafiltered supernatant containing the nonrelated protein Xyl-E and ammonium sulfate-precipitated IgG, purified from a pool of normal 
(nonimmune) sera, were used as negative controls. Monoclonal antibody ISU25C1 and ammonium sulfate-precipitated IgG purified from a pool of hyperimmune sera were used as positive controls. Immunofluorescence was performed with monoclonal antibody SDOW17 (National Veterinary Laboratory Services, NVLS, USDA, IA) that recognizes a highly conserved epitope on PRRSV nucleocapsid protein ${ }^{22}$ and a fluorescein-conjugated anti-mouse IgG $(\mathrm{H}+\mathrm{L})$ antibody (KPL Inc.). Results are expressed as inhibition percentage in FFU as determined by the immunofluorescence assay, after the formula: $100 \times$ sample FFU $\times\left(\right.$ control FFU $\left.{ }^{-1}\right)$.

\section{ELISA tests for assessing C1q Binding}

A dot-ELISA was developed to assess the ability of chimeric antibodies to bind the complement component human C1q, using chimeric IgG1 and IgG2 affinity-purified through protein-A agarose columns followed by ultrafiltration to concentrate the purified proteins. A porcine-IgG standard (Cat. no. P100-105, Bethyl Laboratories, TX) was used as positive control, and a human-IgA standard (Cat. no. P80-102, Bethyl Laboratories, TX) was used as negative control. Two microliters of twofold dilutions (starting at $1 \mu \mathrm{g} /$ $\mu \mathrm{L}$ ) of each antibody were dotted on nitrocellulose membranes at $37^{\circ} \mathrm{C}$ in a humid chamber during an hour. Membranes were gently washed with PBS Tween 20 (PBST) and blocked at $4^{\circ} \mathrm{C}$ overnight with $10 \%$ skim milk in PBST. Human serum (Cat. no. S-1764, Sigma, MO, USA) was used as source of $\mathrm{C} 1 \mathrm{q}$, at a $0.2 \%$ concentration in PBST with $5 \%$ skim milk. C1q binding to membrane-absorbed immunoglobulins was detected with an anti-human complement C1q goat antibody (Fraction IgG) FITC-conjugated (Cat. no. 55166, ICN Pharmaceuticals, OH, USA) diluted 1:2,000, followed by an anti-FITC monoclonal antibody alkaline phosphatase-conjugated (Clone FL-D6, Sigma A-1812, Sigma) in a 1:30,000 dilution. On each step, membranes were incubated during 1 $\mathrm{h}$, followed by a 15-min and two 5-min manual washes with PBST. Dot-ELISA was developed with BCIP/NBT (KPL Inc.). Each sample was studied in duplicates, and the whole experiment was repeated two independent times.

An ELISA test was performed coating 96-well microplates with chimeric or standard antibodies and then following the same procedure described for the Dot-ELISA. Immulon ${ }^{\circledR}$ 2HB plates (ThermoElectron Corp) were sensitized overnight at $4^{\circ} \mathrm{C}$ with twofold dilutions of each antibody in $10 \mathrm{mM}$ carbonate buffer, $\mathrm{pH}$ 9.2. Human serum complement was added at a dilution 1:250 $(0.4 \%)$, anti-human complement C1q was used at a 1:1,000 dilution and monoclonal anti-FITC alkaline phosphatase-conjugated antibody was used at a 1:10,000 dilution. Each reagent was diluted in PBST-5\% skim milk and incubated for $1 \mathrm{~h}$ at room temperature under shaking. Plates were manually washed six times after each step, developed with a soluble form of BCIP substrate (Blue-Phos Microwell Substrate Kit; KPL Inc.) and read at $650 \mathrm{~nm}$.

\section{Results}

\section{Cloning and expression of chimeric IgG1 and IgG2}

Porcine constant lambda and gamma-1 were identical to the reported sequences posted at GenBank (M59322 and U03778, respectively). Porcine gamma-2 showed 99\% identity with both gamma-2a (GenBank no. U03779) and gamma-2b
Table 1. Constant Heavy Chain in Chimeric IgG2 Compared to IgG2a and IgG2b (Aminoacid Multiple Alignment)

\begin{tabular}{lrrrr}
\hline Sequence, Author & \multicolumn{4}{c}{ Amino Acid Residue } \\
\cline { 2 - 5 } (GenBank Accession No.) & 007 & 015 & 018 & 047 \\
\hline IgG2, this paper (EU479715) & $\mathrm{S}$ & $\mathrm{G}$ & $\mathrm{V}$ & $\mathrm{T}$ \\
IGg2a, Kacskovics $^{13}$ (U03779) & $\mathrm{S}$ & $\mathrm{S}$ & $\mathrm{T}$ & $\mathrm{S}$ \\
IgG2b, Kacskovics $^{13}$ (U03780) & $\mathrm{L}$ & $\mathrm{G}$ & $\mathrm{T}$ & $\mathrm{T}$ \\
\hline
\end{tabular}

Val 18 in IgG2 is coded by GTG while Thr 18 in both IgG2a and IgG2b is coded by ACG.

(GenBank no. U03780). Paired comparison with gamma-2a showed nine differences between nucleotides and three amino acid substitutions, $15 \mathrm{G} \rightarrow \mathrm{S}, 18 \mathrm{~V} \rightarrow \mathrm{T}$ and $47 \mathrm{~T} \rightarrow \mathrm{S}$, while comparison with gamma- $2 \mathrm{~b}$ showed five differences at the nucleotide level and two substitutions at the amino acid level, $7 \mathrm{~S} \rightarrow$ $\mathrm{L}$ and $18 \mathrm{~V} \rightarrow \mathrm{T}$ (Table 1). All these differences are located in the $\mathrm{CH} 1$ domain of the molecule. Thus, this sequence represents a mixture of those described as gamma-2a and gamma$2 \mathrm{~b}$, and it was named as "Gamma2." This sequence is available from GenBank under accession number EU479715.

Analysis of the sequences of the variable heavy and light chains from hybridoma ISU25C1 indicated that the heavy chain is encoded by a J558.50 VH gene (Genbank no. AF303881), a DSP-9 D gene (Genbank no. D13199), and a JH2 (Genbank no. V00770) gene with three aminoacid substitutions to the $\mathrm{VH}$ gene, two in framework 1 at positions 13 (G $\rightarrow \mathrm{R})$ and $28(\mathrm{~T} \rightarrow \mathrm{I})$ and one in CDR2 at position $57(\mathrm{D} \rightarrow \mathrm{G})$, but no changes in the D and JH genes (Figure 1, Supporting Information). Analysis of the light sequence indicated a lambda-1 chain using the V $\lambda 1$ gene (Genbank no. V00811) and $\mathrm{J} \lambda 1$ (Genbank X58419) with an aminoacid substitution (A $\rightarrow \mathrm{P}$ ) at position 28 in the CDR1 (Figure 2, Supporting Information). Based on this information, a strategy for cloning the mouse variable genes in frame with the pig constant genes was designed.

Figure 1 (left panel) shows the flowchart and strategy used to clone mouse $\mathrm{V} \lambda$ in frame with porcine constant lambda and mouse $\mathrm{VH}$ coding regions in frame with porcine constant gamma-1 and gamma-2. To clone the mouse lambda variable gene used by monoclonal antibody ISU25C1 in frame with the pig lambda constant genes, we took advantage of the presence of a VN aminoacid sequence at positions 8-9 of the constant region of pig lambda sequence (GTCAAC) and changed it for a Hpa I restriction endonuclease recognition site (GTTAAC) without changing the IgG pig aminoacid sequence. We incorporated this Hpa I sequence in the $3^{\prime}$ end of the reverse primer for the mouse lambda chain variable region, and the $5^{\prime}$ end of the forward primer for the pig lambda chain constant region. All mouse variable heavy antibodies end with either aminoacids VSS or VSA. Mouse VH region used by monoclonal antibody ISU25C1 was reamplified placing an Xba I restriction endonuclease recognition site in the $3^{\prime}$ of the $\mathrm{VH}$ gene, corresponding to the last two codons of the variable coding region. The $\mathrm{VH}$ was cloned in frame with gamma genes using a Nhe I restriction endonuclease recognition site in the $5^{\prime}$ of the gamma regions, restoring the original Ser-Ser aminoacids at the end of the $\mathrm{JH}$ coding region.

A restriction endonuclease recognition site for Bgl II was inserted $5^{\prime}$ to the sequence coding for the VL leader peptide and $3^{\prime}$ to the lambda chain stop codon, while a restric- 


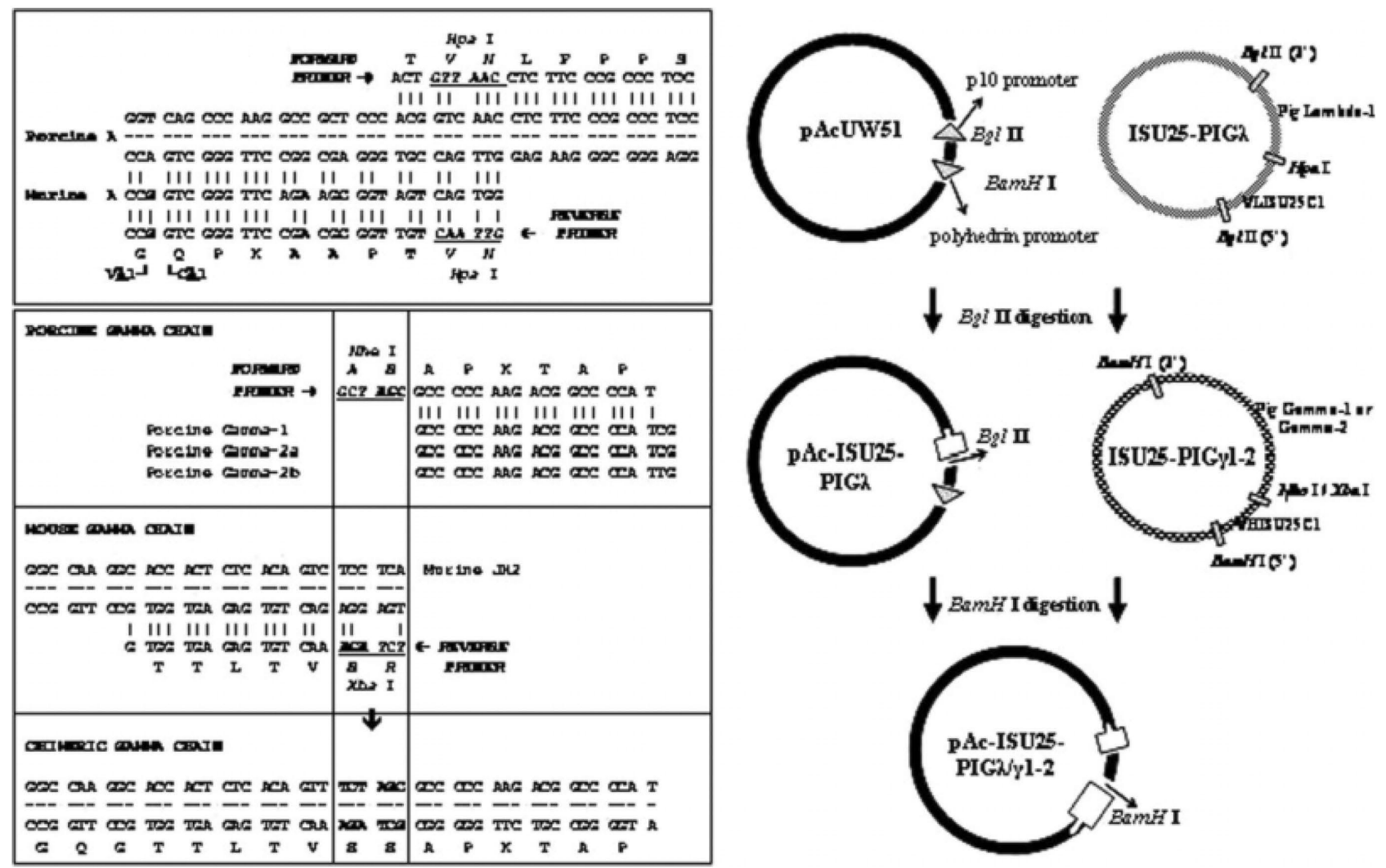

Figure 1. Flow chart and strategy to clone chimeric mouse $\times$ pig IgG1 and IgG2 antibodies.Left panel shows primers used to amplify the $3^{\prime}$ end of variable regions and the $5^{\prime}$ end of constant regions, to clone in frame variable and constant regions in chimeric lambda- 1 chain (upper left) or gamma-1 and gamma-2 chains (lower left). Right panel shows flow chart to clone complete chimeric light and heavy chains in baculovirus transfer vector pAc-UW51.

tion endonuclease recognition site for BamH I was inserted $5^{\prime}$ to the sequence coding for the $\mathrm{VH}$ leader peptide and 3' to the gamma chains stop codons, to allow cloning complete lambda and gamma chains coding sequences in Bgl II and BamH I cloning sites at baculovirus transfer vector pAcUW51 (Figure 1, right panel).

Chimeric antibodies obtained from the supernatants of baculovirus infected-Sf9 cell cultures and purified by ultrafiltration reached concentrations of 30 to $100 \mu \mathrm{g} / \mathrm{mL}$. Gamma-1 and gamma-2 chains from chimeric antibodies showed to be slightly lighter than heavy chains from porcine a Western blot (Figure 2, left panel). Monoclonal antibody

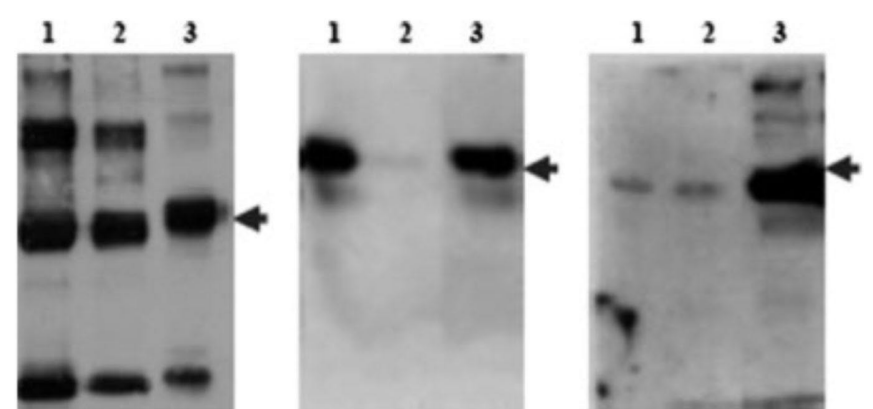

Figure 2. Western blot analysis of baculovirus-expressed mouse $\times$ pig chimeric antibodies developed with chemoluminiscense using anti-porcine IgG $(\mathrm{H}+\mathrm{L})$ (left panel), anti-porcine IgG1 (middle panel), and anti-porcine IgG2 (right panel).Lane 1: chimeric IgG1/ lambda; Lane 2: chimeric IgG2/lambda; Lane 3: porcine purified Igs $(0.5 \mu \mathrm{g} /$ sample). serum but were recognized by an anti-porcine $\operatorname{IgG}(\mathrm{H}+\mathrm{L})$ in K139 3C8 (anti-porcine IgG1) recognized chimeric gamma1 and not gamma-2 (Figure 2, middle panel), while monoclonal antibody K68 Ig2 did not recognize either gamma-1 or gamma-2 (Figure 2, right panel) but did recognize heavy chains from purified serum IgG. This lack of recognition was not due to the different glycosilation pattern showed by chimeric gamma-2 produced in insect cells. K68 Ig2 recognized both glycosilated and deglycosilated porcine total IgG in a Western blot (Figure 3, Supporting Information). To determine the target for $\mathrm{K} 68 \mathrm{Ig} 2$, we tested it against IgG4, since this is the closest to IgG2 in sequence. ${ }^{13}$ We cloned both porcine IgG2 and IgG4 in Vector pGEMEX®, expressed them in $E$. coli and run them in a Western blot. It was shown that

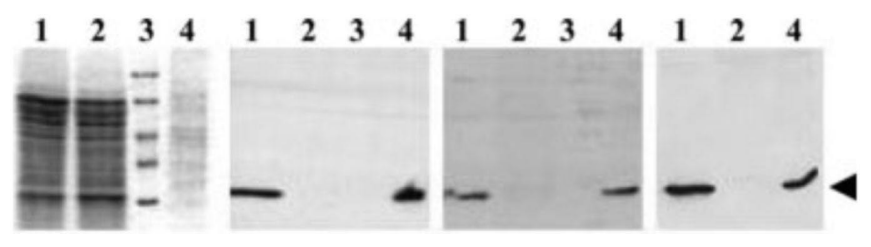

Figure 3. Mouse $\times$ pig-chimeric antibodies recognize PRRSV's GP5.Left panel: PAGE; Middle-left panel: Western blot developed with chimeric IgG1; Middle-right panel: Western blot developed with chimeric IgG2. Right panel: Western blot developed with monoclonal antibody ISU25C1. Lane 1: PRRSV-infected cells, Lane 2: Noninfected cells, Lane 3: MW Marker (116-66.2-45-35-25 kDa), Lane 4: purified PRRSV. Arrow shows apparent molecular weight of $25 \mathrm{kDa}$ 


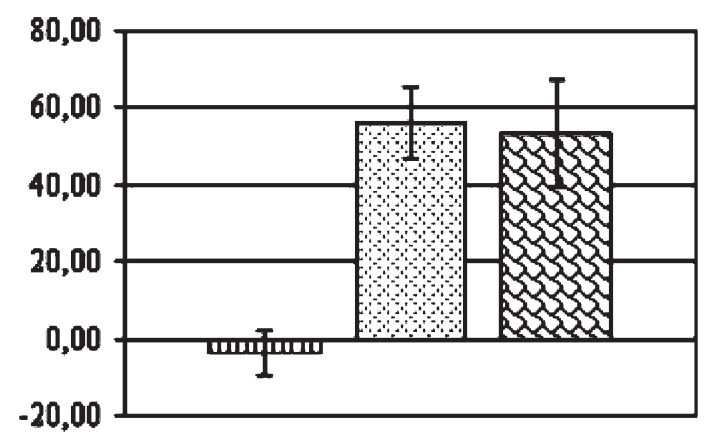

DXY1E 1:2 vIgG1 1:2 aIgG2 1:2

Figure 4. PRRSV neutralization by chimeric antibodies IgG1 and IgG2.Results are expressed as the inhibition percentage in viral foci forming units detected in an immunofluorescence assay (see Materials and Methods).

monoclonal antibody K68 Ig2 recognized IgG4 heavy chain but not IgG2 heavy chain cloned and expressed in the same system (Figure 4, Supporting Information). The main differences between the sequence of chimeric IgG2 and IgG4 reside on the $\mathrm{CH} 3$ domain (94\% identities for aminoacids) and possibly this could be the area recognized by this monoclonal antibody.

Mouse $\times$ porcine chimeric antibodies recognize the epitope in PRRSV described for monoclonal antibody ISU25C1

Both chimeric antibodies recognized PRRSV-infected MARC-145 cells by ELISA. Values shown on Table 2 (left column) correspond to a representative experiment of six independent experiments and are expressed as the normalized OD between PRRSV-infected and noninfected MARC-145 cells. Protein Xyl-E secreted by baculovirus-infected cells concentrated using the same methodology as for the chimeric antibodies was used as a negative control. Cell-culture supernatant from hybridoma ISU25C1 was used as a positive control but was developed with an anti-mouse $(\mathrm{H}+\mathrm{L})$ peroxidase-conjugated antiserum as secondary antibody. Positive (hyper-immune) or negative (nonimmune) porcine sera could not be used in this ELISA because both showed very high background signals against noninfected cells (data not shown). In addition, both chimeric IgG1 and IgG2 antibodies recognized a linear epitope of glycoprotein GP5 (25 kDa), the same protein recognized by monoclonal antibody ISU25C1,

Table 2. Chimeric Antibodies Recognize Cell-Associated (CAV)PRRSV in an ELISA Test and Peptide S4 (PRRSV-GP5 Mimotope) in a Peptide-ELISA Test

\begin{tabular}{lcc}
\hline Sample & ELISA $^{a}$ & Peptide-ELISA $^{b}$ \\
\hline IgG1 $(1.5 \mu \mathrm{g} / \mathrm{mL})$ & $1.132( \pm 0.044)$ & $0.753( \pm 0.045)$ \\
IgG2 $(1.5 \mu \mathrm{g} / \mathrm{mL})$ & $1.417( \pm 0.028)$ & $0.689( \pm 0.039)$ \\
Xyl-E $(1.5 \mu \mathrm{g} / \mathrm{mL})$ & $-0.032( \pm 0.002)$ & $\mathrm{ND}$ \\
Hyperimmune serum & $\mathrm{ND}$ & $1.400( \pm 0.109)$ \\
Negative serum & $\mathrm{ND}$ & $0.195( \pm 0.019)$ \\
ISU25-C1 & $1.980( \pm 0.002)$ & $1.150( \pm 0.032)$ \\
K99 & $-0.008( \pm 0.003)$ & $0.085( \pm 0.006)$ \\
\hline
\end{tabular}

Values of optical densities (ODs) read at $410 \mathrm{~nm}$ are expressed as normalized OD $( \pm \mathrm{SD})$, calculated as $1 / 2\left[\left(\mathrm{OD} M_{\mathrm{s}}-\mathrm{OD} M_{\mathrm{c}}\right)+\left(\mathrm{OD} m_{\mathrm{s}}-\mathrm{OD}\right.\right.$ $\left.m_{\mathrm{c}}\right)$ ], where $M_{\mathrm{s}}$ and $m_{\mathrm{s}}$ are the maximum and minimum values obtained for the samples (a) CAV-PRRSV or (b) Peptide S4, while $M_{c}$ and $m_{c}$ are the maximum and minimum values obtained for the controls (a) noninfected cells or $(b)$ peptide P7. ND, not done. in PRRSV infected MARC-145 cells as well as sucrose-purified PRRSV (Figure 3). In a peptide-ELISA format (Table 2, right column) mouse $\times$ porcine chimeric antibodies recognized the PRRSV-GP5 mimotope represented by peptide S4, the same epitope recognized by monoclonal antibody ISU25C $1{ }^{21}$ This peptide-ELISA was developed with peroxidase-conjugated anti mouse $(\mathrm{H}+\mathrm{L})$ or anti-pig $(\mathrm{H}+\mathrm{L})$ antisera as secondary antibodies. Hyperimmune serum from PRRSV infected pigs with a neutralization titer of 256 also recognized S4 in a peptide-ELISA format using the same peroxidase-labeled anti-pig antiserum used with chimeric antibodies. Thus, mouse $\times$ porcine chimeric antibodies recognized the same protein and epitope as ISU25C1.

\section{Mouse $\times$ pig chimeric IgG1 and IgG2 neutralize PRRS virus}

Cell culture supernatant from hybridoma ISU25C1 inhibits the production of $60 \%$ of viral foci when 100 FFUs of PRRSV are added to MARC-145 cells. ${ }^{16}$ Supernatants from baculovirus infected-Sf9 cells containing chimeric IgGs, semipurified and concentrated by ultrafiltration at a concentration of $15 \mu \mathrm{g} / \mathrm{mL}$, produced an inhibition in viral foci formation that averaged an inhibition of 56\% for IgG1 and $53 \%$ for IgG2 in three different independent experiments, using at least three wells per sample (Figure 4). Supernatants from baculovirus infected-Sf9 cells containing unrelated XylE protein, also semipurified by ultrafiltration, in the same concentration produced no reduction in FFUs. Thus, besides recognition of the same epitope than the original monoclonal antibody ISU25C1, mouse $\times$ pig chimeric antibodies also neutralize PRRSV in a similar fashion as ISU25C1.

Hyperimmune Igs rendered $95 \%$ reduction in viral foci at a concentration of $60 \mu \mathrm{g} / \mathrm{mL}$, while nonimmune Igs rendered no neutralization even at a concentration of $220 \mu \mathrm{g} / \mathrm{mL}$.

\section{Chimeric IgG1 and IgG2 bind human complement C1q}

To test the binding capabilities of pig gamma-1 and gamma-2 to $\mathrm{C} 1 \mathrm{q}$ of human complement, antibodies were studied by ELISA and Dot-ELISA. Complement binding was assessed by addition of a goat anti-human C1q FITCconjugated antibody followed by a peroxidase-conjugated anti-FITC monoclonal antibody. These experiments showed that both pig IgG1 and IgG2 bind human C1q component of complement, with IgG2 being two times more efficient than IgG1 (Table 3 and Figure 5, Supporting Information). Standard porcine IgG behaved in a similar manner than chimeric IgG2. Chimeric IgG2 showed OD values 2.4 times higher than chimeric IgG1, while standard porcine IgG showed OD values 1.8 times higher than chimeric IgG2. Similar results were obtained in a Dot-ELISA format (Figure 5, Supporting Information).

Table 3. ELISA to Detect C1q Binding to Chimeric IgG1 and IgG2

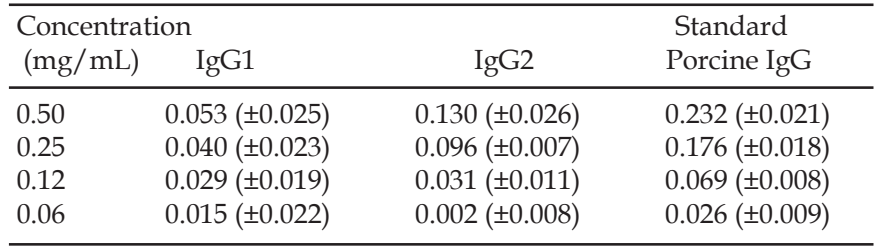

ELISA to detect C1q binding to chimeric IgG1 and IgG2. Standard porcine IgG was used as positive control. Results are expressed as normalized OD $( \pm S D)$. 


\section{Discussion}

In this article, we showed that mouse $\times$ pig chimeric antibodies can be expressed maintaining the binding properties of the mouse Fv as well as properties of the pig constant regions such as complement activation.

The classification of pig IgG subtypes is still under discussion. ${ }^{13,23}$ We produced two chimerics using the constant regions of pig IgG1 and IgG2. The rationale of this selection is based on the fact that at the aminoacid level IgG2a/ IgG2b and IgG4 have a 94\% of identity while IgG1 and IgG3 have a $96 \%$ of identity, compared to $87 \%$ of identity between IgG1 and IgG2a/IgG2b. This data suggest that the two (IgG1 and IgG2) are truly different subisotypes of pig immunoglobulins.

Mab K139 3C8 recognizes pig IgG1 but not IgG2 while Mab K68 Ig2 does not recognize IgG1 or IgG2 (Figure 2). Since IgG4 is the closest to IgG2 in sequence, ${ }^{13}$ we cloned and expressed both IgG2 and IgG4 in bacteria. This IgG4 is recognized in a Western blot by $\mathrm{K} 68 \mathrm{Ig} 2$ monoclonal antibody while IgG2 is not. The main differences between the sequences of chimeric IgG2 and IgG4 resides on the $\mathrm{CH} 3$ domain (94\% identities for aminoacids) and possibly this could be the area recognized by this antibody.

The induction of different IgG subclasses has been correlated with protective immunity in mice, ${ }^{24}$ humans,$^{25}$ cattle, ${ }^{26}$ and other species, but not in pigs. The expression of chimeric mouse $\times$ human antibodies has been useful for the understanding of the functions of the different IgG subclasses. ${ }^{27,} 28$ The expression of chimeric mouse $\times$ pig IgG antibodies helps in the knowledge of the functions of pig IgGs as well as the characterization of these molecular defined antibodies, ${ }^{29}$ and it is a byproduct of this work. To determine the capabilities of chimeric pig IgG1 and IgG2 to activate complement using the classical pathway, C1q was added to the chimeric antibodies in an ELISA and Dot-ELISA formats (Table 3 and Figure 5, Supporting Information). These experiments showed that IgG2 binds complement up to four times better than IgG1. These results are in agreement with previous research that showed that IgG2 obtained from pig serum is more efficient in activating complement that IgG1 measured by lysis of red blood cells. ${ }^{30}$ These authors postulated that the higher flexibility shown by the aminoacids present at the hinge of IgG2 and IgG4 allows for better activation of complement. Thus, the better activation of complement by $\operatorname{IgG} 2 / \operatorname{IgG} 4$ might be due to $\mathrm{C} 1 \mathrm{q}$ activation, and the expression of chimeric mouse $\times$ pig antibodies does not impair this property located in the $\mathrm{CH} 2$ domain.

ISU25C1 binds to an area of GP5 of PRRSV that we previously named epitope $B$ and is the immunodominant neutralizing epitope of PRRSV. ${ }^{21}, 31$ The Fv mouse antibody fragments expressed as chimeric antibodies recognize the same epitope as the original mouse monoclonal antibody ISU25C1 as demonstrated by recognition of PRRSV-infected cells in an ELISA format as well as the peptide S4 in a peptide-ELISA format (Table 2), and PRRSV-GP5 in a Western blot format (Figure 3). Moreover, chimeric antibodies neutralize PRRSV (Figure 4) similar to the parent mouse monoclonal antibody ISU25C1. Thus, expression of mouse Fvs in-frame with pig IgG antibodies does not impair the paratope of the mouse antibodies or the function of neutralization located in this fragment of the parental mouse antibody.
Neutralizing monoclonal antibodies available against PRRSV, including ISU25C1, have low neutralizing activity. ${ }^{16,} 32$ The VDJ gene of ISU25C1 presents two mutations in framework 1 and one in CDR2 compared to putative $\mathrm{VH}$ gene J558.50 and the use of D gene DSP9 read in the third reading frame without mutations (Figure 2, Supporting Information). The low mutation rate in the complementarity determining regions of this antibody suggests that there is no affinity maturation involved in this antibody induced in mice by hypermutation. It seems that the presence of sugars in the area around epitope B covers this epitope from antibodies, since a mutant depleted of glycosylation at positions 34 and 51 is more immunogenic in pigs. ${ }^{33}$ This glycan shielding strategy seems to be also used by HIV and represents an obstacle to develop neutralizing antibodies against HIV in mice. ${ }^{34}$ The production of next generation mouse hybridomas using deglycosilated PRRSV as immunogen would allow for broad and more potent neutralization monoclonal antibodies against PRRSV. These hybridomas could be used in the future as donors of VH-VL genes for the construction of mouse $\times$ pig chimeric neutralizing antibodies against PRRSV using the vectors described here.

Epitope B is also the target to neutralizing antibodies induced in pigs, though the area recognized by these antibodies is different. ${ }^{21}$ This difference might be related to differences in the generation of antibody diversity in pigs. ${ }^{35,} 36$ It is now possible to produce Fvs libraries of pig antibodies. ${ }^{37}$ The combination of this technology with the one described here would allow for the production and expression of $100 \%$ pig antibodies against PRRSV.

Here we show that chimeric mouse $\times$ pig antibodies do maintain the same properties that the parent domains. The production of recombinant antibodies as prophylactic and/ or therapeutic tools in humans has blossomed in the last 10 years. So far, these antibodies are produced in mammalian cells, but different approaches to produce in other less expensive systems are under experimentation. The production in insect cells has shown to be quite expensive and still with unpredictable results. Plants seem to be systems that could produce high quantities at low price and expression has been improved in the last few years. ${ }^{38}$ Thus, chimeric antibodies could be used as preventive and therapeutic tools in animals of economic importance when the technology to produce these antibodies becomes more cost effective. The method used in these experiments would be a universal method for construction of mouse $\times$ pig chimeric antibodies. This strategy could be used alone or accompanying other strategies as vaccination to provide instant immunity in the face of an outbreak and before the establishment of effective adaptive immune response of the pig.

\section{Acknowledgments}

We thank Sygen International and the National Research Initiative of the USDA Cooperative State Research, Education and Extension Service, grant number 2004-35605-14197 (PRRS Coordinated Agricultural Project) for funding support. We also thank Dr. Ken Platt (Iowa State University) for providing us with hybridoma ISU25C1. 


\section{References}

1 Neumann EJ, Kliebenstein JB, Johnson CD, Mabry JW, Bush EJ, Seitzinger AH, Green AL, Zimmerman JJ. Assessment of the economic impact of porcine reproductive and respiratory syndrome on swine production in the United States. J Am Vet Med Assoc. 2005; 227: 385-392.

2 Goldberg TL, Lowe JF, Milburn SM, Firkins LD. Quasispecies variation of porcine reproductive and respiratory syndrome virus during natural infection. Virology. 2003; 317: 197-207.

3 Fang Y, Schneider P, Zhang WP, Faaberg KS, Nelson EA, Rowland RR. Diversity and evolution of a newly emerged North American Type 1 porcine arterivirus: analysis of isolates collected between 1999 and 2004. Arch Virol. 2007; 152: 1009-1017.

4 Osorio FA, Zuckermann F, Wills R, Meier W, Christian S, Galeota J, Doster A. PRRSV: comparison of commercial vaccines in their ability to induce protection against current PRRSV strains of high virulence. Allen D Leman Swine Conf. 1998; 25: 176-182.

5 Pirzadeh B, Dea S. Immune response in pigs vaccinated with plasmid DNA encoding ORF5 of porcine reproductive and respiratory syndrome virus. J Gen Virol. 1998; 79: 989-999.

6 Osorio FA, Galeota JA, Nelson E, Brodersen B, Doster A, Wills R, Zuckermann F, Laegrid WW. Passive transfer of virus-specific antibodies confers protection against reproductive failure induced by a virulent strain of porcine reproductive and respiratory syndrome virus and establishes sterilizing immunity. $\mathrm{Vi}$ rology. 2002; 302: 9-20.

7 Lopez OJ, Oliveira MF, Garcia EA, Kwon BJ, Doster A, Osorio FA. Protection against porcine reproductive and respiratory syndrome virus (PRRSV) infection through passive transfer of PRRSV-neutralizing antibodies is dose dependent. Clin Vacc Immunol. 2007; 14: 269-275.

8 Davies T. Magic bullets. Nature. 1981; 289: 12-13.

9 Kolata G. "The" magic in magic bullets. Science. 1983; 222: 310-312.

10 Marwick C. Monoclonal antibody to treat lymphoma. JAMA. 1997; 278: 616-618.

11 Nissim A, Chernajovsky Y. Historical development of monoclonal antibody therapeutics. Handb Exp Pharmacol. 2008; 181: 3-18.

12 Subramanian KN, Weisman LE, Rhodes T, Ariagno R, Sánchez PJ, Steichen J, Givner LB, Jennings TL, Top FH Jr, Carlin D, Connor E. Safety, tolerance and pharmacokinetics of a humanized monoclonal antibody to respiratory syncytial virus in premature infants and infants with bronchopulmonary dysplasia. MEDI493 Study Group. Pediatr Infect Dis J. 1998; 2: 110-115.

13 Kacskovics Y, Sun J, Butler JE. Five putative subclasses of swine IgG identified from the cDNA sequences of a single animal. J Immunol. 1994; 153: 3565-3573.

14 Lammers BM, Beaman KD, Kim Y. B. Sequence analysis of porcine immunoglobulin light chain cDNAs. Mol Immunol. 1991; 28: 877-880.

15 Sambrook J, Fritsch EF, Maniatis T. Molecular Cloning. A Laboratory Manual. Plainview, NY: Cold Spring Harbor Laboratory Press; 1989.

16 Yang L, Frey ML, Yoon, K-J, Zimmerman JJ, Platt KB. Categorization of North American porcine reproductive and respiratory syndrome viruses: epitopic profiles of the N, M, GP5 and GP3 proteins and susceptibility to neutralization. Arch Virol. 2000; 145: 1599-1619.

17 Bernard O, Hozumi N, Tonegawa S. Sequences of mouse immunoglobulin light chain genes before and after somatic changes. Cell. 1978; 15: 1133-1144.

18 Tonegawa S, Maxam AM, Tizard R, Bernard O, Golbert W. Sequence of a mouse germ-line gene for a variable region of an immunoglobulin light chain. Proc Natl Acad Sci USA. 1978; 75: 1485-1489.

19 Selsing E, Miller J, Wilson R, Storb U. Evolution of mouse immunoglobulin $\lambda$ genes. Proc Natl Acad Sci USA. 1982; 79: 4681-4685.
20 Harlow E, Lane D. Antibodies. A Laboratory Manual. Woodbury, NY: Cold Spring Harbor Laboratory Press; 1988.

21 Ostrowski M, Galeota JA, Jar AM, Platt KB, Osorio FA, Lopez OJ. Identification of neutralizing and nonneutralizing epitopes in the porcine reproductive and respiratory syndrome virus GP5 ectodomain. J Virol. 2002; 76: 4241-4250.

22 Magar R, Larochelle R, Dea S, Gagnon CA, Nelson EA, Christopher-Hennings J, Benfield DA. Antigenic comparison of Canadian and US isolates of porcine reproductive and respiratory syndrome virus using monoclonal antibodies to the nucleocapsid protein. Can J Vet Res. 1995; 59: 232-234.

23 Butler JE, Sun J, Wertz N, Sinkora M Antibody repertoire development in swine. Dev Comp Immunol. 2006; 30: 199-221.

24 Nimmerjahn F, Ravetch JV. Divergent immunoglobulin G subclass activity through selective Fc receptor binding. Science. 2005; 310: 151-152.

25 Bernatowska-Matuszkiewicz E, Pac M, Pum M, Liszka K, Leibl $\mathrm{H}$, Eibl M Ig subclasses and antibody response to pneumococcal capsular polysaccharides in children with severe sinopulmonary infections and asthma. Immunol Invest. 1991; 20: 173-185.

26 Capozzo AV, Periolo OH, Robiolo B, Seki C, La Torre JL, Grigera PR. Total and isotype humoral responses in cattle vaccinated with foot and mouth disease virus (FMDV) immunogen produced either in bovine tongue tissue or in BHK-21 cell suspension cultures. Vaccine. 1997; 15: 624-630.

27 Brüggemann M, Williams GT, Bindon CI, Clark MR, Walker MR, Jefferis R, Waldmann H, Neuberger M. Comparison of the effector functions of human immunoglobulins using a matched set of chimeric antibodies. J Exp Med. 1987; 166: 1351-1361.

28 Dangl JL, Wensel TG, Morrison SL, Stryer L, Herzenberg LA, Oi VT. Segmental flexibility and complement fixation of genetically engineered chimeric human, rabbit and mouse antibodies. EMBO J. 1988; 7: 1989-1994.

29 Bianchi A, Butler JE, Hoorfar J, Howard C, Lind P. Workshop summary: immunoglobulins and Fc receptors. Vet Immunol Immunopathol. 1996; 54: 25-31.

30 Crawley A, Wilkie BN. Porcine Ig isotypes: function and molecular characteristics. Vaccine. 2003; 21: 2911-2922.

31 Plagemann PG, Rowland RR, Faaberg KS. The primary neutralization epitope of porcine respiratory and reproductive syndrome virus strain VR-2332 is located in the middle of the GP5 ectodomain. Arch Virol. 2002; 147: 2327-2347.

32 Cancel-Tirado SM, Evans RB, Yoon K-J. Monoclonal antibody analysis of porcine reproductive and respiratory syndrome virus epitopes associated with antibody-dependent enhancement and neutralization of virus infection. Vet Immunol Immunopathol. 2004; 102: 249-262.

33 Ansari IH, Kwon B, Osorio FA, Pattnaik AK. Influence of Nlinked glycosylation of porcine reproductive and respiratory syndrome virus GP5 on virus infectivity, antigenicity, and ability to induce neutralizing antibodies. J. Virol. 2006; 80: 3994-4004.

34 Burton DR, Stanfield RL, Wilson IA. Antibody vs. HIV in a clash of evolutionary titans. Proc Natl Acad Sci USA. 2005; 102: 14943-14948.

35 Sun J, Hayward C, Shinde R, Christenson R, Ford SP, Butler JE. Antibody repertoire development in fetal and neonatal piglets. I. Four $\mathrm{VH}$ genes account for 80 percent of $\mathrm{VH}$ usage during 84 days of fetal life. J Immunol. 1998; 161: 5070-5078.

36 Pérez C, Wylie D, López O. Variable kappa gene usage in swine antibodies. Medicina (Buenos Aires). 2003; 63: 299-302.

37 Li F, Aitken, R. Cloning of porcine $\mathrm{scFv}$ antibodies by phage display and expression in Escherichia coli. Vet Immunol Immunopathol. 2004; 97: 39-51.

38 Giritch A, Marillonnet S, Engler C, van Eldik G, Botterman J, Klimyuk V, Gleba Y. Rapid high-yield expression of full-size IgG antibodies in plants coinfected with noncompeting viral vectors. Proc Natl Acad Sci USA. 2006; 40: 14701-14706. 